\title{
Physical activity is not associated with spirometric indices in lung-healthy German youth
}

\author{
Maia P. Smith ${ }^{1,2}$, Andrea von Berg ${ }^{3}$, Dietrich Berdel ${ }^{3}$, Carl-Peter Bauer ${ }^{4}$, \\ Barbara Hoffmann ${ }^{5}$, Sibylle Koletzko ${ }^{6}$, Dennis Nowak ${ }^{2,7}$, Joachim Heinrich ${ }^{1,7}$ \\ and Holger Schulz ${ }^{1,7}$
}

\begin{abstract}
Affiliations: 'Institute of Epidemiology 1, Helmholtz Zentrum München - German Research Center for Environmental Health, Munich, Germany. ${ }^{2}$ Institute and Outpatient Clinic for Occupational, Social and Environmental Medicine, Ludwig-Maximilians University, Munich, Germany. ${ }^{3}$ Department of Paediatrics, Marien-Hospital Wesel, Wesel, Germany. ${ }^{4}$ Department of Pediatrics, Technical University of Munich, Munich, Germany. ${ }^{5}$ Leibniz Research Institute for Environmental Medicine and Medical Faculty, Deanery of Medicine, Heinrich Heine University of Düsseldorf, Düsseldorf, Germany. ${ }^{6} \mathrm{Dr}$ von Hauner Children's Hospital, LudwigMaximilians University, Munich, Germany. ${ }^{7}$ Comprehensive Pneumology Center Munich (CPC-M), Member of the German Center for Lung Research, Munich, Germany.
\end{abstract}

Correspondence: Holger Schulz, Helmholtz Zentrum München, Deutsches Forschungszentrum für Gesundheit und Umwelt, Ingolstädter Landstraße 1, 85764 Neuherberg, Germany. E-mail: schulzahelmholtz-muenchen.de

ABSTRACT In lung disease, physical activity improves lung function and reduces morbidity. However, healthy populations are not well studied. We estimate the relationship between spirometric indices and accelerometric physical activity in lung-healthy adolescents.

895 nonsmoking German adolescents without chronic lung disease (45\% male, mean \pm sD age $15.2 \pm 0.26$ years) from the GINIplus and LISAplus cohorts completed questionnaires, spirometry, 7-day accelerometry and an activity diary. Physical activity was measured as minutes, quintiles and regularity of daily moderate, vigorous and moderate-to-vigorous physical activity (MVPA), participation in sport and active commuting to school. Primary outcomes were forced expiratory volume in $1 \mathrm{~s}$ (FEV1), forced vital capacity (FVC), FEV1/FVC and forced expiratory flow at $25-75 \%$ of FVC; they were separately correlated with physical activity and adjusted for confounders of respiratory function, including early-life exposures.

Adolescents averaged 40 min MVPA per day, typical for European youth. 79\% participated in sports and $51 \%$ commuted actively. An association was suggested between $3 \%$ higher FVC $(\sim 100 \mathrm{~mL})$ and either extreme MVPA quintile or percentage of days with $>30$ min MVPA $(p<0.05)$. However, after Bonferroni correction all associations between spirometry, active lifestyle and physical activity were nonsignificant.

Spirometric indices were not significantly associated with active lifestyle or measures of activity in lunghealthy adolescents after adjustment for confounding and multiple-comparison artefacts.

@ERSpublications

In lung-healthy adolescents, spirometric indices were not associated with measures of physical activity http://ow.ly/YN4Nt 


\section{Introduction}

Beneficial health effects of physical activity apply across the lifespan, both in the general population [1] and in populations with chronic diseases including diabetes, neurodegenerative and cardiovascular diseases and cancer. Benefits of physical activity for lung function are known for smokers $[2,3]$ and patients with cystic fibrosis [4], asthma [5, 6] and chronic obstructive pulmonary disease [7]. Accordingly, physical activity has become a standard part of pulmonary rehabilitation $[8,9]$.

The benefits of activity for healthy lungs are less studied. Better lung function [10] and slower age-related decline [11, 12] have been reported in active adults; improved spirometric indices after exercise interventions have been observed in young adults [13, 14]; and athletes have better lung function than sedentary peers in some, but not all, sports [14]. Active school-aged females experienced faster lung growth, but males did not [15]; active children had better lung function [16]; and physically fit children were less likely to develop asthma [5]. These all suggest that physical activity benefits healthy lungs, but are equally consistent with lung-healthy subjects being preferentially active. However, effects are heterogeneous both between and within studies: benefits sometimes appear to be limited to one sex [15] or, in populations of athletes, to particular sports [14].

Furthermore, neither physical activity nor lung function is measured in the same way across studies. Many studies do not consider lung diseases, particularly asthma, which can interact with activity in complex ways $[5,17-20]$. Reported spirometric indices focus on volumes such as forced expiratory volume in $1 \mathrm{~s}(\mathrm{FEV} 1)$ and forced vital capacity (FVC), while flow rates (peak expiratory flow (PEF) and forced expiratory flow $(\mathrm{FEF})$ ) are less often addressed. Lastly, physical activity is often assessed by self-report or parental report, which poorly reflect activity as measured by accelerometry [18]. For all these reasons, evidence for the positive association between physical activity and lung function appears to be suggestive, but not conclusive.

The aim of this study was to investigate this association in nonsmoking adolescents without chronic lung disease (asthma or cystic fibrosis). Spirometric indices (FEV1, FVC, FEV1/FVC, and FEF at 25-75\% of FVC (FEF25-75\%)) were the primary outcomes of our analyses, and we controlled for different early-life factors known to affect lung function. Activity was objectively measured using accelerometry, and activity habits were inferred from participation in sport or active commuting to school.

\section{Methods}

\section{Study population}

We combined spirometry, accelerometric physical activity, physical examinations and interviews from GINIplus (German Infant Study on the Influence of Nutrition Intervention (Plus Environmental and Genetic Influences) on Allergy Development) and LISAplus (Lifestyle-Immune System-Allergy: Influence of Life-style Factors on the Development of the Immune System and Allergies in East and West Germany (Plus the Influence of Traffic Emissions and Genetics)), two cohorts of German Caucasians born between 1995 and 1999 and followed-up at the age of 15 years. Further details of the study designs of GINIplus [21] and LISAplus [22] are published elsewhere; abbreviations are defined in the online supplementary material (appendix 1). Both studies were approved by the respective local ethics committees (the Bavarian General Medical Council and the Medical Council of North Rhine-Westphalia) and by written consent from participating families.

GINIplus was initiated to investigate allergy development after intervention with hydrolysed formulas. Of 5991 healthy, full-term newborns recruited in the regions of Munich and Wesel, 2252 (38\%) with a family

Support statement: The GINIplus study was mainly supported for the first 3 years by the Federal Ministry for Education, Science, Research and Technology (interventional arm) (grant 01 EE 9401-4) and Helmholtz Zentrum Munich (observational arm). The 4-year, 6-year and 10-year follow-up examinations of the GINIplus study were covered by the respective budgets of the four study centres: Helmholtz Zentrum Munich; Research Institute at Marien-Hospital Wesel; Ludwig-Maximilians University Munich; and Technical University Munich, and from 6 years onwards by IUF Leibniz Research-Institute for Environmental Medicine at the University of Düsseldorf and a grant from the German Federal Ministry for the Environment (IUF Düsseldorf, FKZ 20462296). The LISAplus study was mainly supported by grants from the German Federal Ministry for Education, Science, Research and Technology, and in addition from Helmholtz Zentrum Munich; Helmholtz Centre for Environmental Research-UFZ Leipzig; Research Institute at Marien-Hospital Wesel; and Paediatric Practice, Bad Honnef for the first 2 years. The 4-year, 6-year and 10-year follow-up examinations of the LISAplus study were covered by the respective budgets of the involved partners (Helmholtz Zentrum Munich; Helmholtz Centre for Environmental Research - UFZ, Leipzig; Research Institute at Marien-Hospital Wesel; Paediatric Practice, Bad Honnef; and IUF-Leibniz-Research Institute for Environmental Medicine at the University of Düsseldorf) and in addition by a grant from the German Federal Ministry for the Environment (IUF Düsseldorf, FKZ 20462296). This work was supported by the Comprehensive Pneumology Center Munich (CPC-M) as member of the German Center for Lung Research. Funding information for this article has been deposited with FundRef.

Conflict of interest: None declared. 
history of atopy who consented to participate in a randomised trial (nutritional intervention) were randomised in almost equal numbers to either partially or extensively hydrolysed whey, extensively hydrolysed casein or cow's milk formula. The observation arm, made up of 3739 (62\%) unselected children, was given no formula. At 15 years, 3199 adolescents from both study arms were recontacted and approached for accelerometry. Of these, 925 (29\%) completed both accelerometry and spirometry; of these, 665 had complete data on confounders and were nonsmokers without known lung disease. Only these complete cases are included in the analyses. Further details on study design, formulas and follow-up are presented in the online supplementary material (appendices 1 and 2) [21,23].

LISAplus is a population-based cohort of 3097 unselected infants from the cities of Munich, Wesel, Bad Honnef and Leipzig. No intervention, nutritional or otherwise, was used in LISAplus. 1534 subjects were followed-up at the age of 15 years, of which 1107 were from Munich or Wesel and thus approached for accelerometry. Of these, 271 (24\%) completed both accelerometry and spirometry, and 230 were nonsmokers, free of lung disease and provided all data for the model analysis. Study design is detailed in HeINRICH et al. [24].

We thus sampled 895 subjects, 665 from GINIplus and 230 from LISAplus; follow-up is shown in figure 1 and the online supplementary material (appendix 1). Both cohorts are population-based, but the 15-year follow-up is not representative of the underlying study cohorts because of nonrandom loss to follow-up.

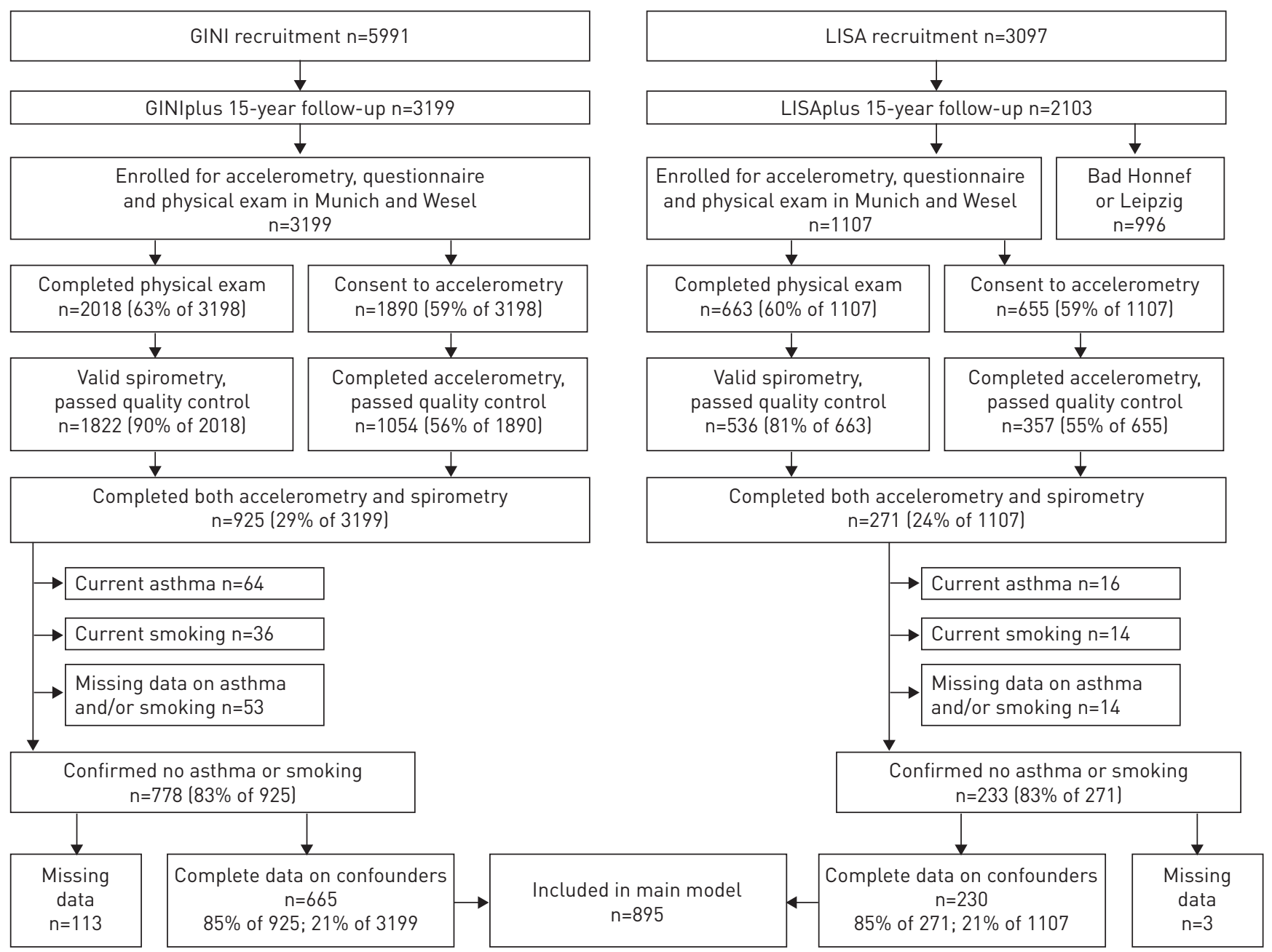

FIGURE 1 GINIplus (German Infant Study on the Influence of Nutrition Intervention (Plus Environmental and Genetic Influences on Allergy Development)) and LISAplus (Lifestyle-Immune System-Allergy: Influence of Life-style Factors on the Development of the Immune System and Allergies in East and West Germany (Plus the Influence of Traffic Emissions and Genetics)) recruitment and follow-up. GINIplus is an ongoing birth cohort study recruited between 1995 and 1999 with the 15-year follow-up addressed in this study (online supplementary material 1 and ginistudie.de). LISAplus is an ongoing birth cohort study recruited between 1995 and July 1998. This study is based on the 15-year follow-up lonline supplementary material 1 and lisastudie.de). Details of accelerometry response rate and quality control are provided in the online supplementary material lappendix 1). 
Information on sociodemographic confounders (e.g. parental education), birthweight, breastfeeding and preand postnatal tobacco exposure up to the age of 6 years were obtained from standardised questionnaires from the initial survey (age 4-6 months) and follow-up to 6 years. Height and weight were measured during the physical examination at 15 years. With respect to the considered confounders, questions and protocols were comparable between GINIplus and LISAplus.

\section{Spirometric protocol}

Spirometry was performed seated, wearing a nose clip and after $15 \mathrm{~min}$ acclimation to the indoor environment, in line with American Thoracic Society/European Respiratory Society recommendations [25]. Subjects performed at least three but not more than eight trials per test to obtain optimal flow-volume curves. Quality guidelines [25] and visual inspection by physicians were applied to exclude manoeuvres incorrectly performed or with artefacts (for more details see [26] and the online supplementary material (appendix 1)). Spirometric indices were taken from the valid manoeuvre with the largest sum of FEV1 and FVC. Indices measured were FEV1, FVC, FEV1/FVC ratio and flow rates (PEF, FEFs). z-scores were based on Global Lung Initiative (GLI) reference values [27].

\section{Accelerometric protocol}

For a detailed description of accelerometer protocol, quality control and data cleaning, see [28] and the online supplementary material (appendix 1). Accelerometers (ActiGraph GT3X; ActiGraph, Pensacola, FL, USA) were worn at the hip. Sampling rate was $30 \mathrm{~Hz}$; accelerations were stored at $1 \mathrm{~Hz}$ and converted into activity levels in 1-min epochs using the algorithm from FrEEDSON et al. [29].

In a standardised diary, subjects documented times of getting up and going to bed, sport and active commuting to school. Valid days had $\geqslant 7-10 \mathrm{~h}$ of valid recording. Valid subjects provided at least three valid weekdays and one valid weekend day. Of the 1689 subjects who returned the accelerometer, 1411 (8832 days) ultimately provided valid data.

\section{Physical activity}

We considered the following physical activity measures. 1) Average daily minutes of moderate, vigorous and moderate-to-vigorous physical activity (VPA and MVPA, respectively); 2) MVPA quintiles, to check for nonlinearity; 3) regularity of MVPA throughout the week (the health effects of short periods of physical activity may differ from those for long periods [30]. For each subject we averaged the fraction of days with $>30,>45$ and $>60$ min MVPA, to create three variables ranging from $0=$ never to $1=$ every day); 4) active commuting, defined as walking or bicycling to school at any point during accelerometry. Participation in sport at least once during accelerometry was also considered.

\section{Exclusion criteria}

\section{Asthma}

Asthma is a lung condition associated with lower physical activity, so to avoid biasing our results, we excluded asthmatics ( $\mathrm{n}=80$; fig. 1). Asthma was defined as at least two of the three following characteristics [31]: asthma diagnosed by a doctor at any year since the age of 3 years. Evaluations were performed at ages 4, 6, 10 and 15 years, with the question asked separately for each year of life since the last examination; asthma medication taken in the past 12 months; asthma symptoms (wheezing or shortness of breath) in the past 12 months.

\section{Other lung diseases}

No children in our study population had cystic fibrosis or other known chronic lung disease.

\section{Smoking}

Only subjects who self-reported current abstinence from tobacco smoking were included in the study. 50 smokers were identified and excluded (fig. 1).

\section{Missing data}

We excluded 67 children with missing data on asthma and/or smoking.

\section{Inclusion criteria}

Of 1011 nonasthmatic, nonsmoking 15-year-olds without cystic fibrosis who completed accelerometry and spirometry, $895(88.5 \%)$ had data on all confounders. To maximise comparability between models we restricted our analysis to these complete cases (fig. 1). 
TABLE 1 Population characteristics

\begin{tabular}{|c|c|c|c|}
\hline & Males & Females & $\begin{array}{c}p \text {-value for } \\
\text { sex difference }\end{array}$ \\
\hline Male & $401(45)$ & & $\# \#$ \\
\hline Age at exam years & $15.2 \pm 0.25$ & $15.2 \pm 0.27$ & \#\# \\
\hline Height at spirometry $\mathrm{cm}$ & $176 \pm 7.6$ & $167 \pm 6.1$ & $<0.0001$ \\
\hline Weight kg & $64.4(63.8 ; 47-85)$ & $58.7(57.2 ; 46-76)$ & $<0.0001$ \\
\hline $\mathrm{BMI} \mathrm{kg} \cdot \mathrm{m}^{-2}$ & $20.6(20.0 ; 17-26)$ & $20.9(20.4 ; 17-26)$ & \#\# \\
\hline Parents highly educated ${ }^{\#}$ & 68 & 70 & $\# \#$ \\
\hline Study centre Munich & 61 & 54 & 0.038 \\
\hline Nutritional intervention" & 36 & 37 & $\# \#$ \\
\hline $\mathrm{BMI}_{\text {category }}{ }^{+}$ & & & 0.28 \\
\hline Underweight & 7.73 & 6.47 & ๆๆ \\
\hline Normal weight & 81.3 & 84.4 & กา \\
\hline Overweight & 8.23 & 5.47 & กๆ \\
\hline Obese & 2.74 & 3.64 & กา \\
\hline FEV 1 L & $3.83 \pm 0.65$ & $3.23 \pm 0.42$ & $<0.0001$ \\
\hline FVC L & $4.50 \pm 0.73$ & $3.66 \pm 0.51$ & $<0.0001$ \\
\hline FEV $1 /$ FVC $\%$ & $85 \pm 5.8$ & $88 \pm 5.8$ & $<0.0001$ \\
\hline FEV1 z-score ${ }^{\S}$ & $-0.55 \pm 0.99$ & $-0.48 \pm 0.91$ & \#\# \\
\hline FVC z-score ${ }^{\S}$ & $-0.56 \pm 0.95$ & $-0.43 \pm 0.91$ & 0.035 \\
\hline FEV $_{1} /$ FVC $z$-score ${ }^{\S}$ & $-0.06 \pm 0.94$ & $-0.075 \pm 0.96$ & \#\# \\
\hline FEF $25-75 \%$ z-score & $-0.43 \pm 0.98$ & $-0.32 \pm 0.88$ & \#\# \\
\hline PEF L.s $\mathrm{s}^{-1}$ & $7.65 \pm 1.3$ & $6.56 \pm 0.95$ & $<0.0001$ \\
\hline FEF $25 \%$ L.S ${ }^{-1}$ & $6.56 \pm 1.3$ & $5.93 \pm 0.91$ & $<0.0001$ \\
\hline FEF $50 \%$ L.s ${ }^{-1}$ & $4.71 \pm 1.2$ & $4.26 \pm 0.86$ & $<0.0001$ \\
\hline FEF75\% L.s ${ }^{-1}$ & $2.31 \pm 0.78$ & $2.15 \pm 0.64$ & $<0.0001$ \\
\hline FEF $25-75 \%$ L.s ${ }^{-1}$ & $4.13 \pm 1.03$ & $3.76 \pm 0.76$ & $<0.0001$ \\
\hline Birthweight $\mathbf{g}$ & $3526 \pm 443$ & $3422 \pm 451$ & 0.0006 \\
\hline Exclusively breastfed & & & \#\# \\
\hline Never & 35 & 35 & กๆ \\
\hline Months $1-4$ only & 10 & 9.11 & กๆ \\
\hline Past month 4 & 55 & 56 & กๆ \\
\hline Mother smoked tobacco when pregnant & 9.47 & 10.3 & $\# \#$ \\
\hline Tobacco smoke at home up to age 6 years & 31 & 30 & $\# \#$ \\
\hline \multicolumn{4}{|l|}{ Activity levels min.day ${ }^{-1} f$} \\
\hline Moderate & $30.8(29 ; 14-54)$ & $25.3(24 ; 9.2-45)$ & $<0.0001$ \\
\hline Vigorous & $14.1(11 ; 2.0-35)$ & $10.3(8.1 ; 0.86-29)$ & $<0.0001$ \\
\hline MVPA & $44.9(42.0 ; 17-83)$ & $35.6(32.1 ; 13-67)$ & $<0.0001$ \\
\hline \multicolumn{4}{|l|}{ MVPA percentage of days } \\
\hline$>30 \mathrm{~min}$ & $56(57 ; 14-100)$ & $48(42 ; 0-100)$ & $<0.0001$ \\
\hline$>45 \mathrm{~min}$ & $39(33 ; 0-86)$ & $28(29 ; 0-71)$ & $<0.0001$ \\
\hline$>60 \mathrm{~min}$ & $26(20 ; 0-71)$ & $16(14 ; 0-57)$ & $<0.0001$ \\
\hline Any sport & 77 & 80 & \#\# \\
\hline Any active commuting to school & 54 & 49 & $\# \#$ \\
\hline
\end{tabular}

Data are presented as $\mathrm{n}(\%)$, mean $\pm \mathrm{SD}$, mean (median; 5th-95th percentiles) or \%, unless otherwise stated. Centrally distributed variables are presented $\mathrm{as}$ mean $\pm \mathrm{SD}$ and $\mathrm{p}$-value from unequal-variance $\mathrm{t}$-test; categorical variables are presented as \% for each category, and p-values from Kruskal-Wallis test; binary variables are presented as $\%$ and $p$-value from Wilcoxon's two-tailed rank-sum test; and skewed variables are presented as mean (median; 5th-95th percentiles) and p-value from Wilcoxon's two-tailed rank-sum test. Population is lung-healthy with complete data; it excludes smokers, asthmatics and those missing data. Moderate, vigorous and moderate-to-vigorous physical activity (MVPA) imputed for diarised nonwear of accelerometer due to sport. BMI: body mass index; FEV1: forced expiratory volume in $1 \mathrm{~s}$; FVC: forced vital capacity; FEF25-75\%, 25\%, 50\% and 75\%: forced expiratory flow at $25-75 \%, 25 \%, 50 \%$ and $75 \%$ of FVC, respectively; PEF: peak expiratory flow. ${ }^{\#}$ : better-educated parent college admission or higher; ${ }^{\natural}:[21,23]$; ${ }^{+}$: according to 10th, 90th and 97th BMI percentiles from a German reference [32]; ${ }^{\S}$ : z-scores from [27]; ${ }^{f}$ : accelerometric cutpoints from $[29,33] ;{ }^{\# \#}: p>0.05 ;{ }^{\text {ๆा }: ~ p-v a l u e ~ g i v e n ~ a s ~ t y p e ~} 3$ for global null hypothesis (top line).

\section{Statistical methods}

All analyses were performed using SAS 9.2 (SAS Institute, Cary, NC, USA). Population characteristics (table 1) are presented as mean $\pm \mathrm{SD}$ for centrally distributed variables, and as mean (median; 5th-95th percentile) for skewed variables such as weight, body mass index (BMI) and VPA. p-values for group 
comparisons were calculated using Wilcoxon's two-tailed rank-sum test for binary and skewed variables, the Kruskal-Wallis test for categorical variables and the t-test for centrally distributed variables.

Statistical models were fit using generalised linear modelling. Spirometric indices and GLI z-scores (FEV1, FVC, FEV1/FVC and $\mathrm{FEF}_{25}$-75\%) were modelled as normally distributed functions of known confounders and one physical activity measure at a time. Inspection of quantile (Q)-Q plots confirmed normality. No model contained either more than one physical activity measure or more than one spirometric index. Confounders were chosen a priori and left in the models regardless of statistical significance. For further details on statistical analysis see the online supplementary material (appendix 2).

Confounders considered were sex, age, height, weight, BMI, study centre, accelerometer weartime, nutritional intervention, parental education, birthweight, breastfeeding and pre- and postnatal tobacco smoke exposure. Alternative models adjusted for subsets of these confounders (the crude and basic models); adjusted further for air pollution (annual average exposure to nitrogen oxides and particles with a $50 \%$ cut-off aerodynamic diameter of $2.5 \mu \mathrm{m}$ ); modelled only the subset of the population without extreme values for spirometry or physical activity; or modelled flows (PEF, FEF25, FEF50 and FEF75) as outcome. Selected models are presented in the main text, and the remainder in the online supplementary material (appendix 3 ).

At $\mathrm{p} \leqslant 0.05$ we have $80 \%$ power to detect a difference of $\sim 100 \mathrm{~mL}$ FEV1 or FVC (3\%) between the top and bottom physical activity quintiles. This is comparable to the effect size estimated in the literature, so we choose the traditional $\mathrm{p} \leqslant 0.05$ to avoid missing an effect. Bonferroni correction is $\mathrm{p} \leqslant 0.0003$ (the basic, crude and main models; four spirometric indices; and 12 physical activity measures, counting each MVPA quintile).

\section{Results}

\section{Study population}

Height, weight and BMI of study participants (table 1) fit the German reference population well [32]. Sociodemographic data confirmed a predominance of highly educated and urban families. Over half were from urban Munich rather than rural Wesel, $10 \%$ were born to mothers who smoked during pregnancy and one-third were exposed to tobacco smoke at home in the first 6 years. 55\% of participants were female, compared to $51 \%$ of the 15 -year follow-up, but otherwise the baseline population was representative of the follow-up population (online supplementary table $1 \mathrm{~b}$ ). However, the 15-year follow-up differed significantly from the original study population (online supplementary table 1c) suggesting differential loss to follow-up.

\section{Lung function}

Mean \pm SD FEV1 and FVC in this sample were $3.83 \pm 0.65 \mathrm{~L}$ and $4.50 \pm 0.73 \mathrm{~L}$, respectively, for males, and $3.23 \pm 0.42 \mathrm{~L}$ and $3.66 \pm 0.51 \mathrm{~L}$, respectively, for females. This is about half a standard deviation below the GLI predicted values [27]; however, Z-score differences between sexes were small. Offset was smaller (online supplementary table 1d) for the German reference values established in the LUNOKID study [34]. However, the two sets of $\mathrm{z}$-scores correlated extremely closely with each other (all $\mathrm{R}^{2}>0.99$ ).

\section{Activity habits}

Each day averaged $\sim 900$ min of accelerometry, of which time two-thirds was sedentary, one-third engaged in light activity and $\sim 5 \%$ in MVPA (table 1). Males were more active than females, but had similar participation levels in sport (77\% and $80 \%$ of males and females, respectively) and active commuting (55\% and $49 \%$ of males and females, respectively). These values are typical for European youth [35] and well below World Health Organization recommendations [36].

\section{Physical activity and spirometric indices}

At $\mathrm{p} \leqslant 0.05$ there was no association between physical activity and any flow index (FEF $25-75 \%$ in tables $2-4$, others in the online supplementary material (appendix 3)) or between any index and either participation in sport or active commuting to school. There was no evidence for a nonlinear effect of MVPA or for confounding by air pollution. Effect estimates were consistent between models of varying complexity.

FVC was associated with both MVPA quintile and percentage of days with $>30$ min MVPA. Although type 3 tests often found no significant difference among all quintiles (global null hypothesis), at $\mathrm{p}<0.05$ pairwise comparisons often showed significantly higher FVC in the most active quintile than the least active, and there was generally a monotone trend across the others (fig. 2a). In the main model (table 2), children in the top quintile of MVPA averaged $113 \mathrm{~mL}$ greater FVC (pairwise $\mathrm{p}<0.02$; global null $\mathrm{p}>0.10$ ) than those in the bottom quintile, and getting $>30$ min MVPA every day, versus never doing so, was associated with $113 \mathrm{~mL}$ increase in FVC $(\mathrm{p}<0.05$.) Effects were similar when outliers were excluded (table 3), when $\mathrm{z}$-scores were modelled as outcome, instead of raw values (table 4) and in simpler models or when air pollution was considered (online supplementary material (appendix 3, tables 1.1-1.3 and 2.1-2.3)). 
TABLE 2 Activity as a correlate of lung function, adjusted for age, sex, height, study centre, nutritional intervention, device weartime, body mass index, parental education, birthweight, exclusive breastfeeding, prenatal tobacco and tobacco smoke at home up to the age of 6 years

\begin{tabular}{|c|c|c|c|c|c|c|c|c|}
\hline & \multicolumn{2}{|l|}{ FEV1 $\mathrm{mL}$} & \multicolumn{2}{|l|}{ FVC mL } & \multicolumn{2}{|l|}{ FEV $1 /$ FVC $\%$} & \multicolumn{2}{|c|}{ FEF $25-75 \% \mathrm{~mL} \cdot \mathrm{s}^{-1}$} \\
\hline & $\begin{array}{c}\text { Parameter } \\
\text { estimate }(95 \% \mathrm{Cl})\end{array}$ & $\mathrm{p}$-value & $\begin{array}{c}\text { Parameter } \\
\text { estimate }(95 \% \mathrm{Cl})\end{array}$ & p-value & $\begin{array}{c}\text { Parameter } \\
\text { estimate }(95 \% \mathrm{Cl})\end{array}$ & p-value & $\begin{array}{c}\text { Parameter } \\
\text { estimate }(95 \% \mathrm{Cl})\end{array}$ & p-value \\
\hline \multicolumn{9}{|l|}{ Daily mean minutes } \\
\hline MPA & $1.009(-1.1-3.1)$ & 0.34 & $1.343(-0.91-3.6)$ & 0.24 & $-0.0048(-0.034-0.024)$ & 0.75 & $1.58(-2.6-5.8)$ & 0.46 \\
\hline VPA & $0.979(-1.6-3.6)$ & 0.46 & $2.636(-0.17-5.4)$ & 0.066 & $-0.0344(-0.070-0.002)$ & 0.060 & $-0.439(-5.7-4.8)$ & 0.87 \\
\hline MVPA & $0.700(-0.66-2.1)$ & 0.31 & $1.296(-0.18-2.7)$ & 0.084 & $-0.0114(-0.030-0.007)$ & 0.23 & $0.554(-2.2-3.3)$ & 0.69 \\
\hline MVPA quintile ${ }^{\#}$ & & 0.22 & & 0.21 & & 0.022 & & 0.050 \\
\hline $1^{\pi}$ & 0 & & 0 & & 0 & & 0 & \\
\hline $2^{\pi}$ & $-5.52(-89-78)$ & 0.90 & $58.1(-33-149)$ & 0.21 & $-1.45(-2.6-0.29)$ & 0.014 & $-172(-342--1.8)$ & 0.048 \\
\hline $3^{\pi}$ & $43.4(-40-127)$ & 0.31 & $63.0(-28-154)$ & 0.18 & $-0.46(-1.6-0.70)$ & 0.44 & $10.1(-160-181)$ & 0.91 \\
\hline $4^{\pi}$ & $-19.0(-103-65)$ & 0.66 & $51.1(-40-142)$ & 0.27 & & 0.0033 & $-155(-326-14.7)$ & 0.073 \\
\hline $5^{\natural}$ & $67.0(-18-151)$ & 0.12 & $113(21-205)$ & 0.016 & $-0.86(-2.0-0.31)$ & 0.15 & $16.1(-156-188)$ & 0.85 \\
\hline \multicolumn{9}{|c|}{ Percentage of days with MVPA } \\
\hline$>30 \mathrm{~min}$ & $96.1(-2.5-195)$ & 0.056 & $113(6.4-221)$ & 0.038 & $-0.331(-1.7-1.0)$ & 0.64 & $117(-84-318)$ & 0.26 \\
\hline$>45 \mathrm{~min}$ & $72.3(-33-177)$ & 0.18 & $95.5(-18-209)$ & 0.10 & $-0.428(-1.9-1.0)$ & 0.56 & $106(109--107)$ & 0.33 \\
\hline$>60 \mathrm{~min}$ & $48.0(-77-172)$ & 0.45 & $98.7(-36-234)$ & 0.15 & $-1.200(-2.9-0.53)$ & 0.17 & $23.6(-230-277)$ & 0.86 \\
\hline Any sport & $34.3(-31-100)$ & 0.30 & $46.6(-25-118)$ & 0.20 & $-0.189(-1.1-0.72)$ & 0.68 & $22.5(-111-156)$ & 0.74 \\
\hline Any active transportation ${ }^{+}$ & $23.9(-32-76)$ & 0.39 & $40.0(-21-95)$ & 0.18 & $-0.189(-0.95-0.54)$ & 0.68 & $11.9(-99-120)$ & 0.83 \\
\hline
\end{tabular}

Data presented in bold are statistically significant at $\mathrm{p}<0.05 .95 \% \mathrm{Cl}$ was calculated using Wald's Chi-squared test. Moderate physical activity (MPA), vigorous physical activity (VPA) and moderate-to-vigorous physical activity (MVPA) imputed for diarised nonwear of accelerometer due to sport. Accelerometric cutpoints were calculated using Freedson's algorithm [29, 33]. FEV1: forced expiratory volume in $1 \mathrm{~s}$; FVC: forced vital capacity; FEF25-75\%: forced expiratory flow at 25-75\% of FVC. \#: p-value for global null hypothesis (i.e. all quintiles equal), quintiles were stratified by sex; ${ }^{n}:$ p-value and parameter estimate for each quintile compared with the lowest (reference); ${ }^{+}$: defined as commuting to school by walking or cycling at least once during accelerometry. 
TABLE 3 Activity as a correlate of lung function, outliers excluded, associations for subjects with moderate physical activity (MPA), vigorous physical activity (VPA), moderate-to-vigorous physical activity (MVPA), forced expiratory volume in $1 \mathrm{~s}$ (FEV1), forced vital capacity (FVC) and FEV1/FVC all within 2 sD of the sex-specific mean, adjusted for age, sex, height, study centre, nutritional intervention, device weartime, body mass index, parental education, birthweight, exclusive breastfeeding, prenatal tobacco and tobacco smoke at home up to the age of 6 years

\begin{tabular}{|c|c|c|c|c|c|c|c|c|}
\hline & \multicolumn{2}{|c|}{ FEV1 $\mathrm{mL}$} & \multicolumn{2}{|c|}{ FVC mL } & \multicolumn{2}{|l|}{ FEV $1 /$ FVC $\%$} & \multicolumn{2}{|c|}{ FEF $25-75 \% \mathrm{~mL} \cdot \mathrm{s}^{-1}$} \\
\hline & $\begin{array}{c}\text { Parameter } \\
\text { estimate }(95 \% \mathrm{Cl})\end{array}$ & p-value & $\begin{array}{c}\text { Parameter } \\
\text { estimate }(95 \% \mathrm{CI})\end{array}$ & p-value & $\begin{array}{c}\text { Parameter } \\
\text { estimate }(95 \% \mathrm{CI})\end{array}$ & p-value & $\begin{array}{c}\text { Parameter } \\
\text { estimate }(95 \% \mathrm{CI})\end{array}$ & $\overline{p \text {-value }}$ \\
\hline \multicolumn{9}{|l|}{ Daily mean minutes } \\
\hline MPA & $1.93(-0.72-4.6)$ & 0.15 & $2.05(-0.80-4.9)$ & 0.16 & $0.0040(-0.033-0.041)$ & 0.83 & $3.01(-2.6-8.6)$ & 0.29 \\
\hline VPA & $1.97(-1.7-5.7)$ & 0.30 & $4.11(-0.18-8.1)$ & 0.041 & $-0.043(-0.094-0.0090)$ & 0.11 & $-2.15(-9.9-5.6)$ & 0.59 \\
\hline MVPA & $-1.37(-0.44-3.2)$ & 0.14 & $1.94(0.0041-3.9)$ & 0.050 & $-0.0083(-0.034-0.017)$ & 0.52 & $0.879(-2.9-4.7)$ & 0.65 \\
\hline MVPA quintile & & 0.27 & & 0.16 & & 0.024 & & 0.078 \\
\hline $1^{9}$ & 0 & & 0 & & 0 & & 0 & \\
\hline $2^{\pi}$ & $28.8(-67-58)$ & 0.89 & $91.4(7.4-175)$ & 0.033 & $-1.27(-2.4--0.18)$ & 0.022 & $-127(-291-36)$ & 0.13 \\
\hline $3^{\pi}$ & $42.6(-50-107)$ & 0.47 & $62.9(-20-146)$ & 0.14 & $-0.46(-1.55-0.62)$ & 0.40 & $9.34(-153-172)$ & 0.91 \\
\hline $4^{\pi}$ & $-2.26(-35-120)$ & 0.28 & $62.4(-22-147)$ & 0.15 & $-1.53(-2.63--0.43)$ & 0.0064 & $-135(-301-30)$ & 0.11 \\
\hline $5^{\pi}$ & $88.4(-1.7-179)$ & 0.055 & $109(13-206)$ & 0.026 & $-0.14(-1.40-1.12)$ & 0.83 & $77.0(-111-265)$ & 0.42 \\
\hline \multicolumn{9}{|c|}{ Percentage of days with MVPA } \\
\hline$>30 \mathrm{~min}$ & $109(7.4-210)$ & 0.035 & $115(6.4-224)$ & 0.038 & $0.142(-1.3-1.6)$ & 0.84 & $139(-74-352)$ & 0.20 \\
\hline$>45 \mathrm{~min}$ & $104(-11-219)$ & 0.076 & $96.2(-27-219)$ & 0.13 & $0.483(-1.1-2.1)$ & 0.56 & $160(-81-400)$ & 0.19 \\
\hline$>60 \mathrm{~min}$ & $75.9(-74-225)$ & 0.32 & $132(-28-292)$ & 0.11 & $-1.026(-3.1-1.1)$ & 0.34 & $-12.0(-325-301)$ & 0.94 \\
\hline Any sport & $-15.4(-79-48)$ & 0.64 & $10.1(-58-78)$ & 0.77 & $-0.600(-1.5-0.30)$ & 0.19 & $-50.0(-183-83)$ & 0.46 \\
\hline Any active transportation ${ }^{+}$ & $-3.10(-55-49)$ & 0.91 & $10.8(-45-67)$ & 0.71 & $-0.333(-1.1-0.40)$ & 0.37 & $-44.3(-154-65)$ & 0.43 \\
\hline
\end{tabular}

Data presented in bold are statistically significant at $\mathrm{p}<0.05 .95 \% \mathrm{Cl}$ calculated using Wald's Chi-squared test. MPA, VPA and MVPA imputed for diarised nonwear of accelerometer due to sport. Accelerometric cutpoints were calculated using Freedson's algorithm [29, 33]. FEF25-75\%: forced expiratory flow at 25-75\% of FVC. \#: p-value for global null hypothesis (i.e. all quintiles equal), quintiles stratified by sex; ${ }^{\text {? }}$ : $p$-value and parameter estimate for each quintile compared with the lowest (reference); ${ }^{+}$: defined as commuting to school by walking or cycling at least once during accelerometry. 
TABLE 4 Activity as a correlate of Global Lung Initiative z-score [27], adjusted for age, sex, height, study centre, nutritional intervention, device weartime, body mass index, parental education, birthweight, exclusive breastfeeding, prenatal tobacco and tobacco at home up to the age of 6 years

\begin{tabular}{|c|c|c|c|c|c|c|c|c|}
\hline & \multicolumn{2}{|c|}{ FEV1 z-score $\times 1000$} & \multicolumn{2}{|c|}{ FVC z-score $\times 1000$} & \multicolumn{2}{|c|}{ FEV 1 /FVC z-score $\times 1000$} & \multicolumn{2}{|c|}{ FEF $25-75 \%$ z-score $\times 1000$} \\
\hline & $\begin{array}{c}\text { Parameter } \\
\text { estimate }(95 \% \mathrm{CI})\end{array}$ & p-value & $\begin{array}{c}\text { Parameter } \\
\text { estimate }(95 \% \mathrm{CI})\end{array}$ & p-value & $\begin{array}{c}\text { Parameter } \\
\text { estimate }(95 \% \mathrm{CI})\end{array}$ & p-value & $\begin{array}{c}\text { Parameter } \\
\text { estimate }(95 \% \mathrm{CI})\end{array}$ & p-value \\
\hline \multicolumn{9}{|l|}{ Daily mean minutes } \\
\hline MPA & $1.93(-2.6-6.5)$ & 0.41 & $2.56(-1.9-7.0)$ & 0.26 & $-0.892(-5.6-3.8)$ & 0.71 & $1.56(-3.1-6.2)$ & 0.51 \\
\hline VPA & $2.22(-3.5-7.9)$ & 0.45 & $5.77(0.26-11.3)$ & 0.040 & $-5.88(-12-0.0041)$ & 0.050 & $-1.24(-7.1-4.6)$ & 0.68 \\
\hline MVPA & $1.43(-1.6-4.4)$ & 0.35 & $2.67(-0.21-5.6)$ & 0.070 & $-1.99(-5.1-1.1)$ & 0.21 & $0.330(-2.7-3.4)$ & 0.83 \\
\hline MVPA quintile ${ }^{\#}$ & & 0.20 & & 0.14 & & 0.016 & & 0.057 \\
\hline $1^{\pi}$ & 0 & & 0 & & 0 & & 0 & \\
\hline $2^{\pi}$ & $-7.20(-192-177)$ & 0.94 & $121(-57-300)$ & 0.18 & $-252(-441--62)$ & 0.0093 & $-188(-376-0.23)$ & 0.050 \\
\hline $3^{\pi}$ & $113(-71-298)$ & 0.22 & $147(-31-327)$ & 0.11 & $-102(-292-89)$ & 0.30 & $21.5(-167-210)$ & 0.82 \\
\hline $4^{\pi}$ & $-29.5(-214-155)$ & 0.75 & $123(-55-302)$ & 0.18 & $-302(-492-112)$ & 0.0018 & $-166(-354-22)$ & 0.083 \\
\hline $5^{\Uparrow}$ & $155(-32-341)$ & 0.10 & $241(60-421)$ & 0.0089 & $-154(-346-38)$ & 0.12 & $9.01(-181-199)$ & 0.93 \\
\hline \multicolumn{9}{|c|}{ Percentage of days with MVPA } \\
\hline$>30$ min & $218(0.72-435)$ & 0.049 & $252(42-462)$ & 0.019 & $-64.7(-289-160)$ & 0.57 & $115(-108-337)$ & 0.31 \\
\hline$>45 \mathrm{~min}$ & $155(-76-386)$ & 0.19 & $204(-20-427)$ & 0.074 & $-76.3(-315-162)$ & 0.53 & $91.7(-144-328)$ & 0.45 \\
\hline$>60 \mathrm{~min}$ & $88.6(-186-363)$ & 0.53 & $203(-62-469)$ & 0.13 & $-217(-500-66)$ & 0.13 & $-15.8(-296-264)$ & 0.91 \\
\hline Any sport & $62.1(-82-206)$ & 0.40 & $82.5(-57-222)$ & 0.25 & $-57.2(-206-92)$ & 0.45 & $21.9(-126-169)$ & 0.77 \\
\hline Any active transportation ${ }^{+}$ & $56.1(-62-175)$ & 0.35 & $72.9(-42-188)$ & 0.21 & $-31.8(-154-90)$ & 0.61 & $16.0(-105-137)$ & 0.80 \\
\hline
\end{tabular}

Data presented in bold are statistically significant at $\mathrm{p}<0.05$. All parameter estimates are multiplied by 1000 for interpretability, e.g. subjects who got $>30$ min moderate-tovigorous physical activity (MVPA) per day averaged a forced vital capacity (FVC) z-score that was 0.252 units higher. $95 \% \mathrm{Cl}$ calculated using Wald's Chi-squared test. Moderate physical activity (MPA), vigorous physical activity (VPA) and MVPA imputed for diarised nonwear of accelerometer due to sport. Accelerometric cutpoints were calculated using Freedson's algorithm [29, 33]. FEV1: forced expiratory volume in $1 \mathrm{~s}$; FEF25-75\%: forced expiratory flow at $25-75 \%$ of FVC. \#: p-value for global null hypothesis (i.e. all quintiles equal), quintiles stratified by sex; ๆ: p-value and parameter estimate for each quintile compared with the lowest (reference); ${ }^{+}$: active transportation defined as commuting to school by walking or cycling at least once during accelerometry. 

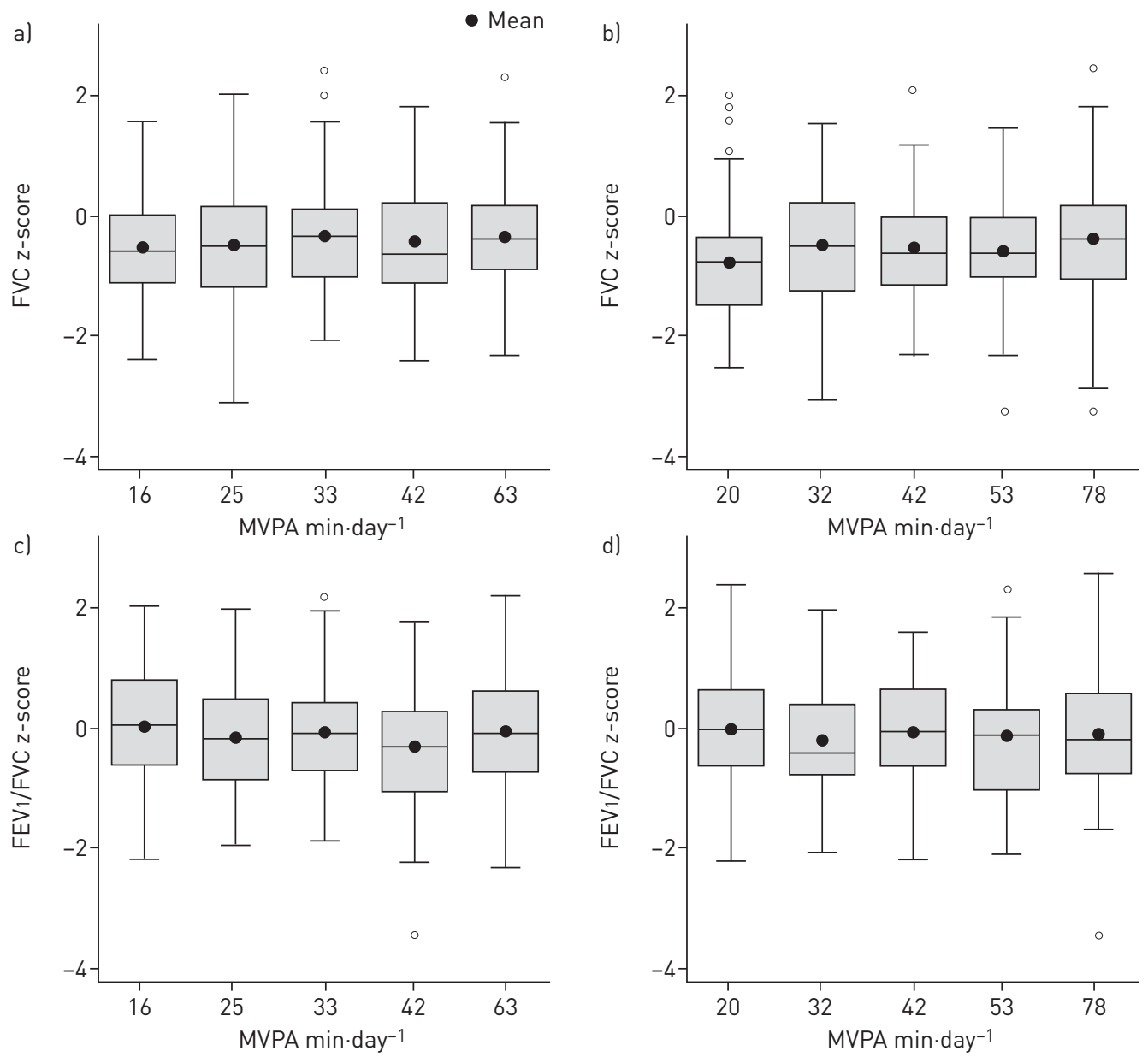

FIGURE 2 Spirometric indices by physical activity quintile. Forced vital capacity (FVC) for a) females and b) males; forced expiratory volume in $1 \mathrm{~s}(\mathrm{FEV} 1) / \mathrm{FVC}$ for $\mathrm{C}$ ) females and d) males. Box and whisker plots show median (25th-75th percentiles) of spirometric z-score and 1.5 interquartile ranges; the mean is represented by a black circle. Spirometric z-scores are from the Global Lung Initiative [27]. Mean daily minutes in moderate-tovigorous physical activity (MVPA) were calculated using Freedson's accelerometric algorithm [29]. Quintiles were calculated separately for each sex.

Relationships with indices other than FVC were often not monotone: for example, the MVPA quintiles that had the most different FEV1/FVC from the least-active (reference) were the second and fourth, not the fifth (highest) (fig. 2b). While PEF was associated at $p \leqslant 0.05$ with VPA and MVPA in the full population, this effect disappeared after the exclusion of outliers. Relationships with spirometric flows (PEF and FEFs) are presented in the online supplementary material (appendix 3, tables 3.1 and 3.2).

After Bonferroni correction, there was no statistically significant relationship between physical activity and any spirometric index.

\section{Discussion}

After correction for multiple comparisons, we found no significant associations in lung-healthy adolescents between physical activity, active lifestyle and spirometric indices. While existing literature suggests that physically active healthy people average $1-10 \%$ higher spirometric volumes, particularly FVC, than inactive peers $[10,13,15,16,37]$, in athletes these effects were found only in some sports [14], and in one study [13] FVC declined by $4 \%$ after 8 weeks of aerobic exercise. We found that at $\mathrm{p} \leqslant 0.05$ only the association between FVC and either percentage of days with $>30$ min MVPA or extreme MVPA quintile, was both robust across models and consistent with a monotone trend between spirometry and physical activity. The observed difference of $113 \mathrm{~mL} \mathrm{FVC} \mathrm{(3 \% )} \mathrm{between} \mathrm{top} \mathrm{and} \mathrm{bottom} \mathrm{MVPA} \mathrm{quintile} \mathrm{was} \mathrm{consistent} \mathrm{with} \mathrm{the} \mathrm{literature}$ $[10,13,15,16,37]$; however, results for other indices often were not plausible, such as larger spirometric differences between intermediate MVPA quintiles than between extreme quintiles. To reduce multiple comparisons we suggest that further research focuses on spirometric indices chosen a priori, such as FVC. 
Possible reasons for the discrepancies between studies may include statistical models used, study population, confounding, correction for multiple comparisons or physical activity measurement methods; measurement methods for lung function were comparable. We accelerometrically measured physical activity in adolescents and considered levels, thresholds and lifestyle, while other studies [10,13,15, 16, 37] mostly studied younger children, relied on physical activity questionnaires, and/or dichotomised physical activity into active versus nonactive.

While we considered nonlinear effects by modelling MVPA quintiles and thresholds in addition to continuous minutes, we may have missed a more complex relationship. The association between FVC and percentage of days with $>30 \mathrm{~min}$ of MVPA, but no higher threshold, hints at nonlinearity. Although almost the whole population ( $87 \%$ of subjects) had participated in sport and/or commuted actively, physical activity was highly variable: 5th and 95th percentiles were 15 and 75 min per day, respectively, MVPA, and 1.2 and $31 \mathrm{~min}$, respectively, VPA. Nevertheless, the full range of physical activity may not have been sampled. In light of findings in athletes, who experienced $\sim 5 \%$ higher spirometric volumes [14], our observed physical activity may have been insufficient to measurably affect lung function.

Furthermore, activity type may be important in determining size or direction of the association between physical activity and lung function: some sports were associated with increased volumes, others were associated with no difference and others with decreases [14]. Although we found no change in spirometry with participation in sport, we did not consider the type of sport, and with regards to total physical activity, one sport associated with increased FVC $(\sim 6 \%)$ was cycling, which accelerometry is known to undermonitor [38].

\section{Strengths and limitations}

The strength of our study is that we applied several different quantifications of physical activity and measured physical activity objectively with accelerometry rather than questionnaires: only $1-10 \%$ of the variance of accelerometric physical activity is captured by self-report [18] and this error is not likely to be uniform across subjects. However, accelerometry also has well-known limitations, including the "snapshot" nature of data recorded over the course of a single week and the known undermonitoring of low-acceleration sports [38]. Although participants may be more active when they know measurement is taking place [39], our subjects were no more active on the first weekday of accelerometry than on the others, which suggests that this effect is negligible. Likewise, although spirometry is the standard measurement of lung function, it does not measure mechanical properties of the lung, respiratory pump functions or gas-exchange capacity, although in the healthy lung close correlations have been reported with FVC.

Well-known limitations arise from our cross-sectional design. Selection bias began with the recruitment of German Caucasians born full-term and continued with selective loss to follow-up by the age of 15 years; successful completion of accelerometry, examinations and questionnaires at the age of 15 years may have introduced further bias. Relative to GINIplus and LISAplus at birth, we oversampled females from urban Munich and well-educated families who breastfed more and smoked less, all of which may indicate greater health-consciousness. The intervention arm of GINIplus (selected for atopy risk) was more likely to be followed-up successfully than the unselected observation arm, further suggesting a health-consciousness bias. However, representation of the four different nutritional interventions did not change and FEV 1 and FVC did not vary between study formulas [40], suggesting that the intervention itself did not drive results. Thus, while we adjusted for conditions that may affect lung function, and carefully excluded smokers, asthmatics or those with suspected asthma, residual effects cannot be ruled out and our findings may not generalise to all populations.

\section{Conclusion}

In a cohort of healthy and active adolescents, we found no clear evidence for an association between spirometric indices and physical activity or activity habits.

\section{Acknowledgements}

This study was part of the 15-year follow-up of two German birth cohorts, GINIplus and LISAplus. We thank the GINIplus and LISAplus study groups for all their excellent work.

The GINIplus study group includes the following. J. Heinrich, I. Brüske, H. Schulz, C. Flexeder, C. Zeller, M. Standl, M. Schnappinger, M. Sußmann, E. Thiering and C. Tiesler: Institute of Epidemiology I, Helmholtz Zentrum München German Research Center for Environmental Health, Munich, Germany; D. Berdel, A. von Berg and B. Filipiak-Pittroff: Research Institute, Department of Paediatrics, Marien-Hospital, Wesel, Germany; S. Koletzko and K. Werkstetter: Ludwig-Maximilians-University of Munich, Dr von Hauner Children's Hospital, Munich; C.P. Bauer and U. Hoffmann: Department of Paediatrics, Technische Universität München and Deutsche Rentenversicherung Bayern, Munich; and B. Hoffmann, E. Link, C. Klümper and U. Krämer: IUF-Leibniz Institute for Environmental Research, Düsseldorf, Germany.

The LISAplus Study Group includes the following. J. Heinrich, I. Brüske, H. Schulz, M. Standl, M. Schnappinger, M. Sußmann, E. Thiering, C. Tiesler, C. Flexeder and C. Zeller: Institute of Epidemiology I, Helmholtz Zentrum München, 
German Research Center for Environmental Health, Munich, Germany; A. von Berg: Department of Paediatrics, Marien Hospital Wesel, Wesel, Germany; B. Schaaf: Paediatric Practice, Bad Honnef, Germany; C.P. Bauer and U. Hoffmann: Technical University, Munich; I. Lehmann, M. Bauer, G. Herberth, J. Müller, S. Röder and M. Schilde: Helmholtz Centre for Environmental Research - UFZ, Department of Environmental Immunology/Core Facility Studies, Leipzig, Germany;

M. Borte, U. Diez, C. Dorn and E. Braun: Department of Paediatrics, Municipal Hospital "St Georg", Leipzig; and M. Ollert and J. Grosch: ZAUM - Center for Allergy and Environment, Technical University Munich.

\section{References}

1 Wen CP, Wai JP, Tsai MK, et al. Minimum amount of physical activity for reduced mortality and extended life expectancy: a prospective cohort study. Lancet 2011; 378: 1244-1253.

2 Garcia-Aymerich J, Lange $\mathrm{P}$, Benet $\mathrm{M}$, et al. Regular physical activity modifies smoking-related lung function decline and reduces risk of chronic obstructive pulmonary disease: a population-based cohort study. Am J Respir Crit Care Med 2007; 175: 458-463.

3 Garcia-Aymerich J, Lange P, Benet M, et al. Regular physical activity reduces hospital admission and mortality in chronic obstructive pulmonary disease: a population based cohort study. Thorax 2006; 61: 772-778.

4 Schneiderman JE, Wilkes DL, Atenafu EG, et al. Longitudinal relationship between physical activity and lung health in patients with cystic fibrosis. Eur Respir J 2014; 43: 817-823.

5 Rasmussen F, Lambrechtsen J, Siersted HC, et al. Low physical fitness in childhood is associated with the development of asthma in young adulthood: the Odense schoolchild study. Eur Respir J 2000; 16: 866-870.

6 Lucas SR, Platts-Mills TA. Physical activity and exercise in asthma: relevance to etiology and treatment. J Allergy Clin Immunol 2005; 115: 928-934.

7 Güell R, Casan P, Belda J, et al. Long-term effects of outpatient rehabilitation of COPD: a randomized trial. Chest 2000; 117: 976-983.

8 Fairclough S. Physical activity, perceived competence and enjoyment during secondary school physical education. Eur J Phys Educ 2003; 5-18.

9 Ries AL, Bauldoff GS, Carlin BW, et al. Pulmonary rehabilitation: joint ACCP/AACVPR evidence-based clinical practice guidelines. Chest 2007; 131: Suppl. 5, 4S-42S.

10 Nystad W, Samuelsen SO, Nafstad P, et al. Association between level of physical activity and lung function among Norwegian men and women: the HUNT study. Int J Tuberc Lung Dis 2006; 10: 1399-1405.

11 Pelkonen M, Notkola IL, Lakka T, et al. Delaying decline in pulmonary function with physical activity: a 25-year follow-up. Am J Respir Crit Care Med 2003; 168: 494-499.

12 Trappe S, Hayes E, Galpin A, et al. New records in aerobic power among octogenarian lifelong endurance athletes. J Appl Physiol 2013; 114: 3-10.

13 Fatima SS, Rehman R, Saifullah KY. Physical activity and its effect on forced expiratory volume. J Pak Med Assoc 2013; 63: 310-312.

14 Mazic S, Lazovic B, Djelic M, et al. Respiratory parameters in elite athletes - does sport have an influence? Rev Port Pneumol 2015; 21: 192-197.

15 Ji J, Wang SQ, Liu YJ, et al. Physical activity and lung function growth in a cohort of Chinese school children: a prospective study. PLoS One 2013; 8: e66098.

16 Berntsen S, Wisløff T, Nafstad P, et al. Lung function increases with increasing level of physical activity in school children. Pediatr Exerc Sci 2008; 20: 402-410.

17 Beuther DA, Sutherland ER. Overweight, obesity, and incident asthma: a meta-analysis of prospective epidemiologic studies. Am J Respir Crit Care Med 2007; 175: 661-666.

18 LeBlanc AG, Janssen I. Difference between self-reported and accelerometer measured moderate-to-vigorous physical activity in youth. Pediatr Exerc Sci 2010; 22: 523-534.

19 Ferrari P, Friedenreich C, Matthews CE. The role of measurement error in estimating levels of physical activity. Am J Epidemiol 2007; 166: 832-840.

20 Williams B, Powell A, Hoskins G, et al. Exploring and explaining low participation in physical activity among children and young people with asthma: a review. BMC Fam Pract 2008; 9: 40.

21 Heinrich J, Brüske I, Schnappinger M, et al. German Interventional and Nutritional Study. Helmholtz Zentrum Muenchen, Institut für Epidemiologie I.

22 Chen CM, Rzehak P, Zutavern A, et al. Longitudinal study on cat allergen exposure and the development of allergy in young children. J Allergy Clin Immunol 2007; 119: 1148-1155.

23 von Berg A, Krämer U, Link E, et al. Impact of early feeding on childhood eczema: development after nutritional intervention compared with the natural course - the GINIplus study up to the age of 6 years. Clin Exp Allergy 2010; 40: 627-636.

24 Heinrich J, Brüske I, Schnappinger M, et al. LISAplus: Influence of Life-style Factors on the Development of the Immune System and Allergies in East and West Germany Plus the Influence of Traffic Emissions and Genetics. Germany, Institut für Epidemiologie I, Helmholtz Zentrum Muenchen, Deutsches Forschungszentrum für Gesundheit und Umwelt (GmbH).

25 Miller MR, Hankinson J, Brusasco V, et al. Standardisation of spirometry. Eur Respir J 2005; 26: 319-338.

26 Flexeder C, Thiering E, von Berg A, et al. Peak weight velocity in infancy is negatively associated with lung function in adolescence. Pediatr Pulmonol 2016; 51: 147-156.

27 Quanjer PH, Stanojevic S, Stocks J, et al. GLI-2012: All-Age Multi-Ethnic Reference Values for Spirometry. Global Lung Initiative, 2012.

28 Pfitzner R, Gorzelniak L, Heinrich J, et al. Physical activity in German adolescents measured by accelerometry and activity diary: introducing a comprehensive approach for data management and preliminary results. PLoS One 2013; 8: e65192.

29 Freedson P, Pober D, Janz KF. Calibration of accelerometer output for children. Med Sci Sports Exerc 2005; 37 Suppl. 11, S523-S530.

30 Marschollek M. A semi-quantitative method to denote generic physical activity phenotypes from long-term accelerometer data - the ATLAS index. PLoS One 2013; 8: e63522. 
31 Jarvis D, Newson R, Lotvall J, et al. Asthma in adults and its association with chronic rhinosinusitis: the GA2LEN survey in Europe. Allergy 2012; 67: 91-98.

32 Kromeyer-Hauschild $\mathrm{K}$, Wabitsch M, Kunze D, et al. Perzentile für den Body-Mass-Index für das Kindes- und Jugendalter unter Heranziehung verschiedener deutscher Stichproben. [Percentiles of body mass index in children and adolescents evaluated from different regional German studies]. Monatsschr Kinderheilkd 2001; 149: 807-818.

33 Trost SG, Loprinzi PD, Moore R, et al. Comparison of accelerometer cut points for predicting activity intensity in youth. Med Sci Sports Exerc 2010; 43: 1360-1368.

34 Hüls A, Krämer U, Gappa M, et al. Neue spirometrische Referenzwerte für Kinder und Jugendliche in Deutschland unter Berücksichtigung der Größe und nichtlinearer Alterseffekte: Die LUNOKID-Studie. [New spirometric reference values for children and adolescents in Germany considering height and non-linear age effects: the LUNOKID-study]. Pneumologie 2013; 67: 141-149.

35 Ruiz JR, Ortega FB, Martínez-Gómez D, et al. Objectively measured physical activity and sedentary time in European adolescents: the HELENA study. Am J Epidemiol 2011; 174: 173-184.

36 World Health Organization. Information Sheet: Global Recommendations on Physical Activity for Health 18-64 Years Old. Geneva, World Health Organization, 2011.

37 Holmen TL, Barrett-Connor E, Clausen J, et al. Physical exercise, sports, and lung function in smoking versus nonsmoking adolescents. Eur Respir J 2002; 19: 8-15.

38 Robertson W, Stewart-Brown S, Wilcock E, et al. Utility of accelerometers to measure physical activity in children attending an obesity treatment intervention. J Obes 2011; 2011: 398918.

39 Dössegger A, Ruch N, Jimmy G, et al. Reactivity to accelerometer measurement of children and adolescents. Med Sci Sports Exerc 2014; 46: 1140-1146.

40 von Berg A, Filipiak-Pittroff B, Hoffmann U, et al. Allergic manifestation 15 years after early intervention with hydrolyzed formulas - the GINI Study. Allergy 2016; 71: 210-219. 